\title{
Análise de Lineamentos Estruturais no Domo de Lages (SC) com Uso de Imagens de Satélite e Mapas de Relevo Sombreado
}

\section{Analysis of the Structural Lineaments in the Domo de Lages, State of Santa Catarina, Using Satellite Images and Shaded Relief Maps}

\author{
Luis Fernando Roldan' (Ifroldan@gmail.com), Rômulo Machado² (rmachado@usp.br), \\ Samar dos Santos Steiner' (samar.steiner@gmail.com), Lucas Veríssimo Warren' (warren@usp.br) \\ 'Programa de Pós-graduação em Geoquímica e Geotectônica - Instituto de Geociências - USP \\ R. do Lago 562, CEP 05508-080, São Paulo, SP, BR \\ ${ }^{2}$ Departamento de Geologia Sedimentar e Ambiental - Instituto de Geociências - USP, São Paulo, SP, BR
}

Recebido em 13 de maio de 2009; aceito em 22 de março de 2010

\section{RESUMO}

Este trabalho apresenta o estudo dos lineamentos estruturais na região do Domo de Lages, porção centro-sul do Estado de Santa Catarina, e sua relação com as diferentes unidades estratigráficas da Bacia do Paraná que ocorrem na região. Os lineamentos estruturais foram interpretados a partir da análise digital de imagens de satélite e de mapas de relevo sombreado, com o uso de técnicas de geoprocessamento. Os resultados mostram lineamentos estruturais com orientações NW, NNE, NE, ENE e E-W. Os lineamentos maiores (4 - $50 \mathrm{~km}$ ) foram interpretados a partir dos mapas de relevo sombreado, enquanto os menores (1 - $3 \mathrm{~km}$ ) foram interpretados a partir da imagem de satélite. De acordo com os dados de campo, estes lineamentos afetam rochas vulcânicas da Formação Serra Geral da Bacia do Paraná e rochas alcalinas associadas ao domo. Em todas estas direções estruturais são encontradas evidências de falhas transcorrentes. A formação das falhas transcorrentes destrais NNE tem sido relacionada a uma tensão compressiva orientada NE-SW. Considera-se que a idade máxima de geração dessas orientações estruturais situa-se no limite do Cretáceo Superior ao Paleógeno. A formação dessas estruturas tem sido relacionada à reativação de estruturas mais antigas presentes na bacia e no seu embasamento.

Palavras-chave: Domo de Lages; Lineamentos estruturais; Geoprocessamento; Falhas transcorrentes.

\begin{abstract}
This work focuses on the study of structural lineaments in the Domo de Lages region, central-south area of Santa Catarina State, and their relationship with the different stratigraphic units of the Paraná Basin that are present in this area. The lineaments were interpreted from Landsat and shaded relief images, using geoprocessing techniques. The results show structural lineaments with NW, NNE, NE, ENE and E-W trends. The larger lineaments (4 - $50 \mathrm{~km})$ were interpreted using shaded relief maps, whereas the smaller lineaments were interpreted using satellite images $(1-3 \mathrm{~km})$. According to field data, these lineaments affect the volcanic rocks of Serra Geral Formation (Paraná Basin) and alkaline rocks associated with the dome. In all these structural trends, evidences of transcurrent faults were found. The formation of transcurrent faults with NNE trend has been related to compressive NE-SW stress. Late Cretaceous/Paleogene is the maximum age considered for the development of these structural trends associated with transcurrent faults. The formation of this structural pattern has been linked to the reactivation of older structures present in the basin and its basement.
\end{abstract}

Keywords: Domo de Lages; Structural lineaments; Geoprocessing; Transcurrent faults. 


\section{INTRODUÇÃO}

O Domo de Lages localiza-se logo a norte da cidade homônima, na porção centro-sul do estado de Santa Catarina (Figuras 1A e 1B). Corresponde a uma região da borda leste da Bacia do Paraná, caracterizada pela ocorrência de rochas alcalinas de idade mesozoica, que tem sido alvo de investigações principalmente de natureza mineralógica e petrológica (Scheibe, 1986), sendo escassos trabalhos que abordam aspectos estruturais e morfotectônicos.

O Domo de Lages corresponde a uma janela estratigráfica onde unidades mais antigas da bacia afloram em cotas similares às das unidades mais novas. Em planta, corresponde a uma estrutura concêntrica alongada, com eixo maior NW-SE, que expõe na parte central rochas do Subgrupo Itararé e em direção às bordas unidades sucessivamente mais jovens que afloram nas bordas (Figura 1C). O fechamento nordeste da estrutura envolve unidades do Grupo São Bento e ocorre fora da área do mapa apresentado. As ocorrências de rochas alcalinas são mais comuns na parte sul do domo, em particular dos corpos maiores.

Scheibe (1986) separou as rochas alcalinas do domo nos seguintes grupos: alcalinas leucocráticas (fonólitos, analcima traquitos e nefelina sienitos), alcalinas ultrabásicas (olivina melilitos e lamprófiros, geralmente na forma de diques), além de carbonatitos, kimberlitos e brechas de chaminé, que compõem o então denominado "Distrito Alcalino de Lages".

Dados radiométricos, obtidos pelo método K/Ar em rochas alcalinas da região, forneceram idades entre $63 \mathrm{Ma}$ a $78 \mathrm{Ma}$, enquanto as determinações $\mathrm{Rb} / \mathrm{Sr}$ forneceram uma idade isocrônica de $81 \pm 8 \mathrm{Ma}$, situando o magmatismo no Neo-Cretáceo e, portanto, sendo posterior ao magmatismo associado à Formação Serra Geral da Bacia do Paraná (Scheibe, 1986; Scheibe et al., 1985).

Os trabalhos de cartografia geológica em escala de semidetalhe que vêm sendo desenvolvidos na região têm mostrado que várias ocorrências de rochas alcalinas, descritas inicialmente como intrusivas na forma de stocks, correspondem, na realidade, a corpos concordantes, com geometria tabular (sills), intrusivos na Formação Serra Alta, preferencialmente na parte superior da unidade. Estes corpos, com espessura em geral da ordem de dezenas de metros $(<100 \mathrm{~m})$, encontram-se associados com depósitos de bauxita, denotando uma ação significativa da atuação dos processos de natureza exógena ligados à bauxitização, que foram instalados após o período de exumação do domo e exposição dos corpos alcalinos à superfície.

Este trabalho apresenta o resultado da análise de lineamentos de diferentes produtos digitais (imagem de satélite e mapas de relevo sombreado) da região do Domo de La- ges - SC e busca estabelecer um quadro de evolução cronológica dessas estruturas e sua correlação com as estruturas regionais definidas na borda leste da Bacia do Paraná, nos estados de Santa Catarina e Paraná.

\section{ARCABOUÇO TECTÔNICO REGIONAL}

No arcabouço tectônico da Bacia do Paraná destacamse três padrões estruturais principais: NW-SE, NE-SW e E-W (Zalán et al., 1987). Os dois primeiros padrões são considerados os mais importantes e representam descontinuidades já existentes no embasamento da bacia, que foram reativadas sucessivamente durante a sua evolução, e podem corresponder a falhas simples ou extensas zonas de falhas (comprimento de centenas de $\mathrm{km}$ e largura de poucas dezenas de km), por vezes associadas à estruturas-emflor, dobras e falhas reversas escalonadas ou grandes falhas normais.

Cabe salientar que as direções estruturais NW e NE da bacia são as que apresentam o mais alto índice de concordância entre os elementos dos mapas gerados por diferentes fontes de dados, enquanto as demais direções (NNE, ENE, NNW, WNW) apresentam índices muito baixos (Soares et al., 2007).

Durante a ruptura continental do Gondwana, ocorrida no Juro-Cretáceo, o padrão estrutural NW sofreu reativação, enquanto o padrão $\mathrm{NE}$, encontrado no embasamento adjacente e relacionado com movimentação transcorrente, não teria sido reativado e, ao contrário do padrão NW, não estaria associado à colocação de diques básicos (Zalán et al., 1987).

No embasamento pré-cambriano do escudo catarinense ressaltam-se lineamentos com direções estruturais dominantes NE e NNE e direções isoladas NW (Figura 1B). Putzer (1952), ao estudar o comportamento das camadas de carvão no sul de Santa Catarina, se refere ao Sistema de Fraturas Catarinense e descreve diques básicos que cortam rochas Paleozoicas e preenchem fraturas conjugadas N0-30E, N60W e E-W. Falhas transcorrentes destrais N0-10E e sinistrais N50-60E são descritas como estruturas que controlam a mineralização de fluorita e barita no distrito fluorítico do sudeste de Santa Catarina (Ferreira e Almeida, 1989). Tais estruturas, de idade mesozoica (pós-Grupo Passa Dois), reativaram lineamentos mais antigos presentes no referido escudo. Padrão estrutural similar é encontrado na continuação do embasamento da Bacia no Paraná, ressaltando, no entanto, os de orientação N30-40E e ao redor de N60E. Na região do Arco de Ponta Grossa, além dos grandes enxames de diques básicos NW-SE, destacam-se também expressivos lineamentos magnéticos paralelos aos mesmos (ver Schobbenhaus et al., 1984). 

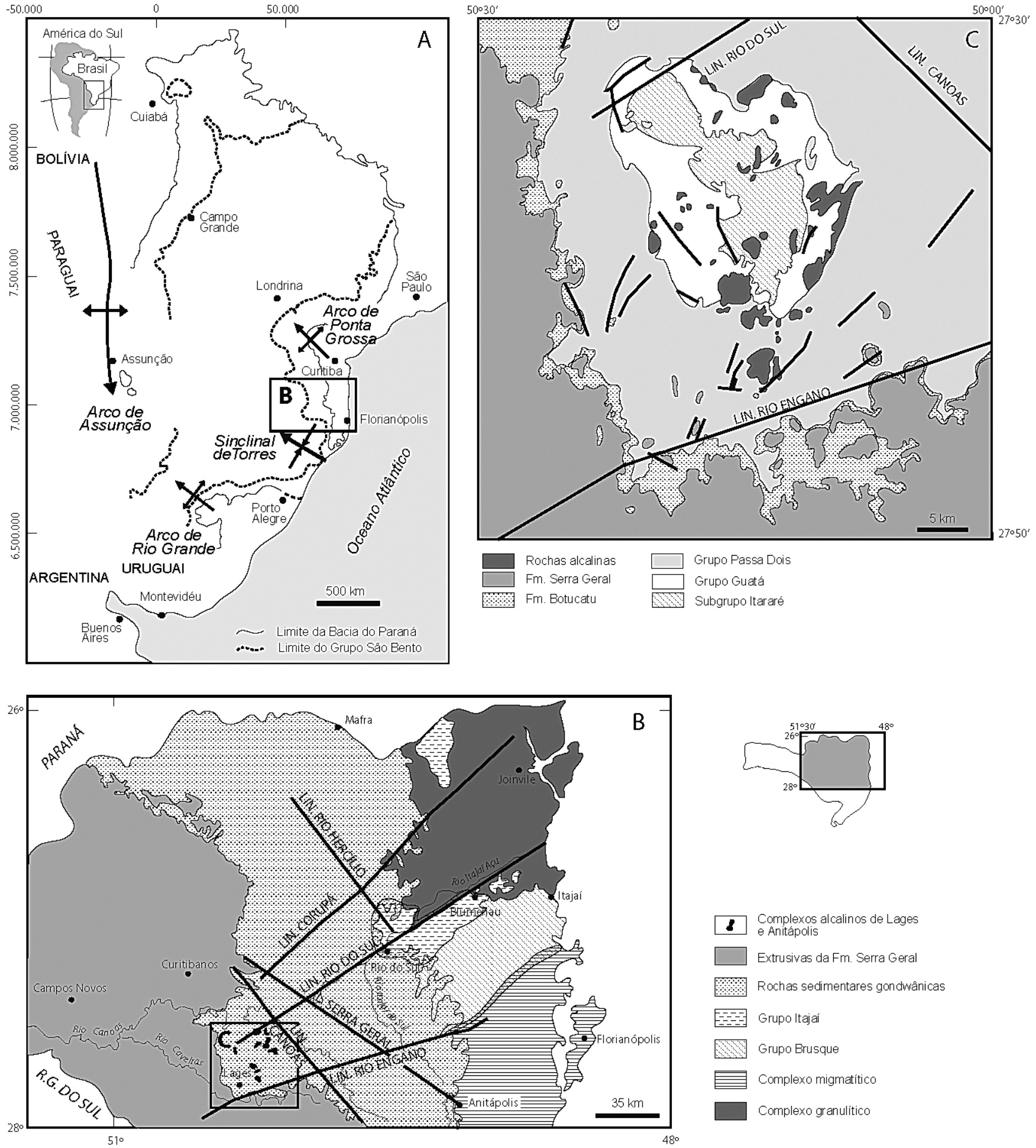

Figura 1. A. Contexto geológico regional da área estudada com indicação das principais feições estruturais da borda leste da Bacia do Paraná (Modificado de Strugale et al., 2007). B. Contexto geológico da porção centro-leste do Estado de Santa Catarina mostrando os principais lineamentos estruturais da borda leste da Bacia do Paraná e do escudo catarinense (Modificado de Scheibe, 1979 e Roldan, 2007). C. Mapa geológico da área estudada (Simplificado de Roldan, 2007). 
Os estudos estruturais e geofísicos, em escalas de semidetalhe e regional, realizados em várias regiões do $\mathrm{Pa}$ raná (Quatiguá, Prudentópolis, Jaguariaíva) e divisa com o estado de Santa Catarina, têm mostrado a existência de falhas transcorrentes NE, sinistrais e destrais, e falhas distensionais NW, estas últimas exibindo também cinemática sinistral (Rostirolla et al., 2000; Machado e Rostirolla, 2005; Freitas e Rostirolla, 2005; Santos, 2005).

Evolução tectônica similar ao da estrutura de Quatiguá é encontrada em São Paulo na borda leste da Bacia do Paraná, região de Ipeúna e Charqueada, no Alto Estrutural de Pitanga, onde falhas transcorrentes com direção ENE e WSW, destrais, e falhas transcorrentes NNW e NW, sinistrais, têm sido caracterizadas na região (Soares, 1976; Soares et al., 1996; Riccomini, 1995). As falhas com direção NW e NNW não são registradas nos sedimentos cenozoicos da Formação Rio Claro (Riccomini, 1995).

\section{DOMO DE LAGES}

Os trabalhos pioneiros realizados sobre a geologia e a tectônica da região de Lages definiram a estrutura regional como sendo um domo vulcânico, do tipo perfurante, com formato circular, onde as camadas do Super Grupo Tubarão sofreram elevação da ordem de 1.100 a 1.200 m (Loczy, 1968). O magmatismo alcalino foi considerado como sendo posterior à deposição do Membro Morro Pelado (Formação Rio do Rasto) e anterior à deposição da Formação Botucatu. Descreve-se, na parte central da estrutura, uma cobertura sedimentar intensamente fraturada e falhada com presença de falhas de empurrão primitivas, que exibem simetria radial e concêntrica em relação à estrutura central.

Scheibe (1986), ao estudar a mineralogia e petrologia das rochas alcalinas da região de Lages, apresenta um mapa geológico da Folha Lages (SG-22-Z-C-V) na escala 1:100.000, abrangendo toda a estrutura dômica e as ocorrências de rochas alcalinas a ela associadas. Na cartografia apresentada pelo autor, além de ser evidente a geometria do domo, são representadas as unidades litoestratigráficas da Bacia do Paraná que afloram na região, figurando na parte central rochas pertencentes ao Subgrupo Itararé e na parte externa rochas do Grupo São Bento. A Figura 1B mostra um esboço geológico regional com os principais lineamentos da porção centro-oriental do estado de Santa Catarina, onde figuram lineamentos NE (Corupá e Rio do Sul), ENE (Rio Engano) e NW (Rio Hercílio, Serra Geral e Rio Canoas) (Figura 1B). Os lineamentos NE e ENE estão presentes no Escudo Catarinense e afetam a sequência gondwânica da bacia, com este último passando logo a sul de Lages e se estendendo até as vulcânicas da Formação Serra Geral. Os lineamentos NW afetam apenas a sequência gondwânica (ver Figura 1B).
Trabalhos de cartografia geológica em escala de semidetalhe que vêm sendo realizados pelos autores no Domo de Lages têm incorporado novas informações, permitindo com isso a confecção de um mapa geológico atualizado que apresenta novos aspectos da geologia da região, tais como a colocação das rochas alcalinas, cujas relações de campo mostram claramente que várias de suas ocorrências descritas anteriormente como corpos intrusivos discordantes do tipo stocks, a exemplo do Morro do Tributo, ponto culminante da região $(1200 \mathrm{~m})$, correspondem, na realidade, a corpos concordantes do tipo sills, alojados, em geral, no topo da Formação Serra Alta. São encontradas também intrusões concordantes alojadas no Subgrupo Itararé.

O mapa da Figura 1C, gerado a partir de um banco de dados em programa SIG (Sistemas de Informações Geográficas), mostra a configuração concêntrica alongada do Domo de Lages, com eixo maior NW-SE. Expõe na parte central da estrutura rochas do Subgrupo Itararé, seguidas para periferia de rochas dos grupos Guatá (Formações Itararé e Palermo), Passa Dois (Formações Irati, Serra Alta, Teresina, Rio do Rasto) e das formações Piramboia/Botucatu e Serra Geral. O fechamento da estrutura se dá com as rochas vulcânicas da Formação Serra Geral, a sul e a oeste, e, com o Grupo Passa Dois, a norte e a leste.

As rochas alcalinas distribuem-se em praticamente toda a região do domo, havendo, porém, maior incidência de corpos na porção sul da estrutura, onde acompanham muitas vezes os contatos dos grupos Passa Dois e Guatá. Corpos alcalinos são encontrados também no Subgrupo Itararé. O mapa apresentado assinala os lineamentos NW, NE e NNE (Figura 1B).

O Domo de Lages, localizado na borda leste da Bacia do Paraná no estado de Santa Catarina (Figura 1A), situa-se entre duas estruturas tectônicas NW regionais importantes da bacia: o Arco de Ponta Grossa, a norte, e o Sinclinal de Torres, a sul. O primeiro é caracterizado por uma área que se manifestou como uma feição positiva no final do Permiano, situação que se acentuou na passagem do Jurássico para o Cretáceo, ocorrendo importante soerguimento acompanhado da intrusão de expressivo enxame de diques básicos, que serviram de condutos para extrusão do magmatismo da Formação Serra Geral (Almeida, 1983; Zalán et al., 1987, 1990; Rostirolla et al., 2000; Strugale et al., 2003, 2007; Freitas e Rostirolla, 2005, dentre outros). Trabalhos de modelagem geofísica, realizados nesta região, apontam os seguintes valores de extensão crustal (NE-SW): 18\% (Ferreira et al., 1989) e 12\% (Portela Filho et al., 2005). Falhas transcorrentes de direção NW são também descritas por Zalán et al. (1987) na Bacia do Paraná. Especificamente no Arco de Ponta Grossa, algumas delas apresentam caráter destral e são concomitantes à colocação dos diques (Strugale et al., 2003, 2007). 
O Sinclinal de Torres, ao contrário, tem sido considerado como uma feição tectônica com comportamento de tendência negativa, pelo menos desde o final do Jurássico Superior ao início do Cretáceo. Nele, as rochas da Bacia do Paraná foram preservadas da intensa erosão que afetou regiões vizinhas soerguidas como os arcos de Ponta Grossa e do Rio Grande, situados, respectivamente, a norte e a sul do mesmo. Infelizmente, são escassos na literatura trabalhos que discutam o comportamento dessa estrutura. A localização do Domo de Lages entre duas feições tectônicas regionais de tendência ascensional sugere não apenas uma relação geométrica entre elas, mas que tenha conexão com o processo tectônico regional.

Almeida (1983), em seu trabalho sobre a tectônica das rochas alcalinas mesozoicas na porção meridional da Plataforma Sul-americana, chama atenção para o fato do Domo de Lages estar localizado na região de inflexão entre duas grandes estruturas tectônicas regionais, o Arco de Ponta Grossa e o Sinclinal de Torres, bem como relaciona as rochas alcalinas de Lages à Província Alcalina de Santa Catarina, e considera a possibilidade delas estarem associadas à reativação tectônica de falhas tardi-brasilianas situadas ao sul de Santa Catarina.

Embora a existência de altos estruturais e domos na Bacia do Paraná seja um fato conhecido há tempos, a sua origem é uma questão ainda em aberto entre os pesquisadores. Alguns desses altos são nitidamente associados com intrusões alcalinas, a exemplo do Domo de Lages, enquanto em outros altos estas rochas não foram registradas, sugerindo nestes casos origem provavelmente tectônica.

As feições dômicas, com ou sem intrusões alcalinas, configuram altos estruturais. Almeida (1983) chama atenção para a ocorrência mais numerosa de rochas alcalinas nas margens da Bacia do Paraná ou nas suas bordas imediatas, onde o embasamento pré-siluriano está exposto, e salienta a relação destas rochas com arcos ativos durante $o$ magmatismo ou mesmo em tempos mais antigos (arcos de Assunção e Ponta Grossa).

Vários autores salientam a importância da reativação tectônica de estruturas do embasamento pré-cambriano na formação de altos estruturais nas unidades fanerozoicas da Bacia do Paraná e ressaltam que a movimentação de falhas antigas foi um processo determinante na deformação do seu arcabouço (Almeida, 1969, 1983; Soares et al., 1982; Zalán et al., 1987, 1990; Riccomini, 1995; Rostirolla et al., 2000, dentre outros). Incluem-se, neste contexto, os altos estruturais de Pitanga (Riccomini, 1992, 1995; Riccomini et al., 1991; Sousa, 1998, 2002; Sousa e Morales, 1999, 2003; Soares et al., 1996), Jacu e Carlota Prenz (Riccomini, 1995), Artemis e Pau D'Alho (Sousa, 1998, 2002; Sousa e Morales, 2003) e Jiboia
(Sousa, 2002; Souza e Morales, 2003; Batista, Morales, Sousa, 2002) em São Paulo; Quatiguá, no Paraná (Soares et al., 1996; Rostirolla et al., 2000) e Lages, em Santa Catarina (Loczy, 1966, 1968; Almeida, 1983; Scheibe, 1986; Roldan, 2007). Outros modelos têm sido considerados para explicar a formação de estruturas dômicas na bacia: o de intrusões de rochas alcalinas (Loczy, 1966), o de falhas indiferenciadas, dobras (ou ambos), subsidência da bacia como um todo (Soares, 1974), e o de impacto de meteoritos, a exemplo das estruturas de Vargeão (SC), Cerro do Jarau (RS) e Piratininga (SP) (Hachiro et al., 1993, 1994).

Estudos sobre as rochas carbonatíticas do sudeste do Brasil consideram o magmatismo de Lages relacionado a um estágio mais avançado do processo de rifteamento continental, enquanto o de Anitápolis, situado mais a leste, é considerado contemporâneo ao estágio inicial desse processo. Neste contexto, o magmatismo de Lages é relacionado à cadeia Rio Grande-Walvis (CominChiaromonti et al. $(2002,2003)$.

Riccomini et al. (2005), ao agruparem as rochas alcalinas brasileiras, incluem as rochas de Lages no setor sul da Província Serra do Mar. Os autores ressaltam o forte controle exercido por descontinuidades existentes no embasamento, marcadas principalmente por zonas de falhas extensionais e transcorrentes presentes nas bordas atuais das bacias sedimentares. Relacionam o magmatismo, principalmente às mudanças nos campos de esforços e a reativação de estruturas regionais, ocorridas durante os diversos pulsos magmáticos desencadeados entre o Permo-Triássico e o Paleógeno. Para os autores, o magma alcalino teria ascendido na crosta através de diferentes zonas de fraqueza, chegando à superfície ou se alojando em profundidade em rochas mais antigas.

\section{MÉTODOS UTILIZADOS}

\section{Geoprocessamento}

Foi implementado um banco de dados georreferenciados no programa SIG (Sistemas de Informações Geográficas), com as informações disponíveis (mapas, fotos e imagens), sendo sistematizadas e somadas com os produtos obtidos a partir da interpretação das imagens de satélite (Landsat-TM e composições RGB) e dos levantamentos de campo. As atividades foram realizadas no programa ArcGis, versão 9.0.

As cartas topográficas foram digitalizadas e georreferenciadas, com exceção da folha Lages 1:100.000 em que foi utilizada sua versão vetorizada, obtida diretamente do banco de dados georreferenciado do IBGE. As imagens de satélite e as fotos aéreas foram tratadas no programa 
ENVI, versão 4.2, sendo também georreferenciadas e adicionadas no banco de dados. Utilizou-se a base geológica do mapa em escala 1:100.000, de Scheibe (1986), que foi digitalizado e atualizado por Steiner (2004).

A implementação do banco de dados, além de permitir a integração das informações existentes, auxiliou na obtenção dos subprodutos, como os mapas de lineamentos aqui apresentados. Cada subproduto gerado foi automaticamente adicionado ao banco de dados, incrementando as informações da área e facilitando a análise conjunta dos dados.

\section{Modelo Digital de Terreno}

O Modelo Digital de Terreno da área estudada foi elaborado a partir da base de dados da missão espacial SRTM - Shutle Radar Topographic Mission - da Nasa, disponibilizado gratuitamente no site http://seamless.usgs.gov. Tais produtos possuem resolução espacial de 1 arc sec $(\sim 30 \mathrm{~m})$, para os Estados Unidos, e de 3 arc sec $(\sim 90 \mathrm{~m})$, para os outros países. A aquisição das informações altimétricas se baseia na interferometria entre dados obtidos de um mesmo ponto na superfície, a partir de duas posições diferentes. Atualmente, os dados pré-processados do projeto SRTM no território nacional podem ser obtidos diretamente no site da Embrapa (http://www.relevobr.cnpm.embrapa.br/).

A resolução espacial de $90 \mathrm{~m}$, embora seja adequada para as análises regionais, mostra-se inadequada para análises que exigem maior detalhe. Neste sentido, para aumentar a definição do modelo, utilizou-se a alternativa do método da reamostragem com interpolação por médias móveis, conforme proposto por Grohmann e Steiner (2006), onde a resolução espacial do modelo passa a ser de $30 \mathrm{~m}$. Esta metodologia, apesar de não aumentar o nível de detalhe do modelo original, proporciona maior coerência angular entre pontos vizinhos de uma superfície e elimina os ruídos inerentes aos dados brutos. O método consiste basicamente em um ajuste do variograma e de parâmetros de Krigagem, considerando os seguintes passos: 1) modelagem do variograma a partir dos resíduos da superfície de tendência de primeira ordem, garantindo assim o dado geoestacionário; 2) uso somente de dados da vizinhança imediata do ponto analisado, em função da sua alta correlação espacial da superfície topográfica; 3 ) adição, antes da interpolação, de uma variação aleatória muito pequena às coordenadas dos pontos, 4) uso de um valor pequeno do efeito pepita, a fim de evitar uma suavização que altere as características do terreno.

O modelo obtido foi adicionado ao banco de dados SIG que, juntamente com a utilização de técnicas e ferramentas do programa ArcGIS, permitiram a elaboração dos mapas de relevo sombreado.

\section{Imagens de satélite}

Foram utilizadas imagens de satélite com composições RGB, bandas 3, 4, e 5, e LANDSAT-TM, banda 8 (pancromática), com resolução espacial de $15 \mathrm{~m}$, ambas correspondentes a cena 221/79 (data de aquisição em 12 de novembro de 2002 , azimute solar $41,1 \mathrm{~g}$, e inclinação solar $34,1 \mathrm{~g})$. A primeira imagem foi obtida gratuitamente no site da EMBRAPA (http://www.relevobr.cnpm.embrapa.br/), Coleção Brasil Visto do Espaço (2000), e a segunda foi fornecida pelo INPE.

Os lineamentos identificados nas duas imagens foram traçados diretamente no programa SIG, gerando-se a partir dos mesmos dois mapas distintos. Depois, os dados foram integrados para confecção de um mapa final, tomando-se o cuidado de remover os lineamentos repetidos, a fim de evitar a distorção estatística.

A extração dos lineamentos foi realizada a partir de duas bases distintas: uma com o uso da imagem de satélite (banda pancromática com resolução espacial de $15 \mathrm{~m}$ ), e outra com o uso de mapas de relevo sombreado obtidos com diversas direções de iluminantes, a partir do modelo digital de terreno.

\section{Análise dos lineamentos}

Os lineamentos foram considerados na concepção de O'Leary et al. (1976) como sendo feições lineares de uma superfície, mapeável, simples ou composta, cujas partes encontram-se alinhadas de forma retilínea ou ligeiramente curva, que diferem das feições adjacentes e refletem provavelmente estruturas de subsuperfície.

Para identificação dos lineamentos da área estudada seguiu-se os procedimentos propostos por Liu (1987) e Riccomini e Crosta (1988). A análise dos lineamentos foi realizada segundo o método de multiescala e com o uso de produtos digitais de fontes distintas: imagens de satélite (composições RGB e LANDSAT-TM) e mapas de relevo sombreado com várias direções de iluminantes.

Os fotolineamentos foram digitalizados diretamente na tela do computador sobre a imagem de satélite, usando-se critérios e metodologia empregados por Liu $(1984,1987)$. A análise dos lineamentos, em termos de comprimento e direção, foi realizada com o uso de planilhas do programa Excel.

Os mapas de relevo sombreado foram obtidos, inicialmente, com oito direções distintas de iluminantes (N, S, E, $\mathrm{W}, \mathrm{NE}, \mathrm{NW}, \mathrm{SE}$ e $\mathrm{SW}$ ), todos posicionados a $35^{\circ}$. Devido às cotas elevadas nas porções sul e oeste da área, os iluminantes orientados a E, NE, N e NW forneceram os melhores resultados (Figura 2). Apesar da imagem de satélite apresentar uma resolução espacial melhor que a dos mapas 


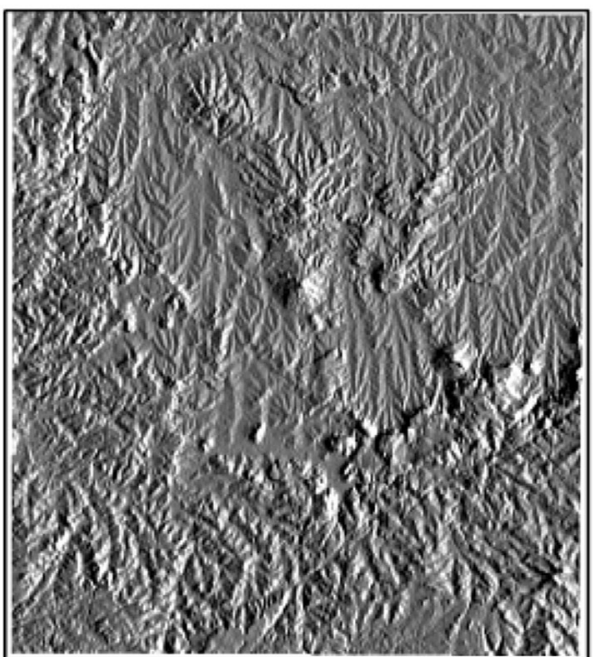

A

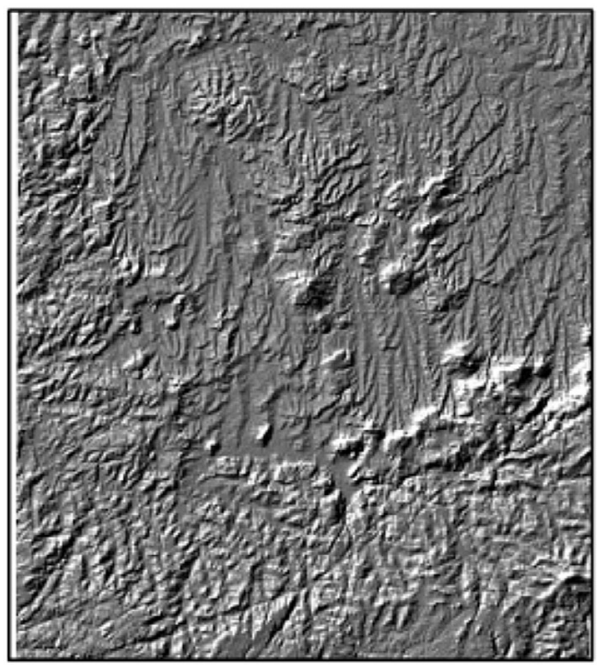

C

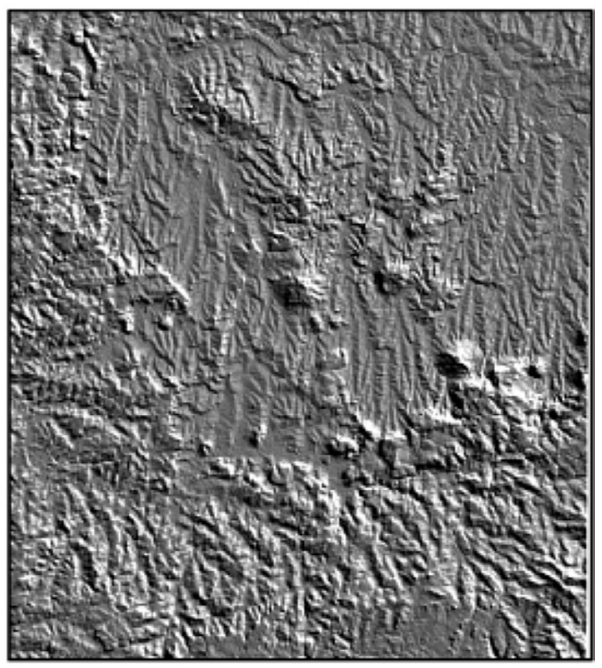

B

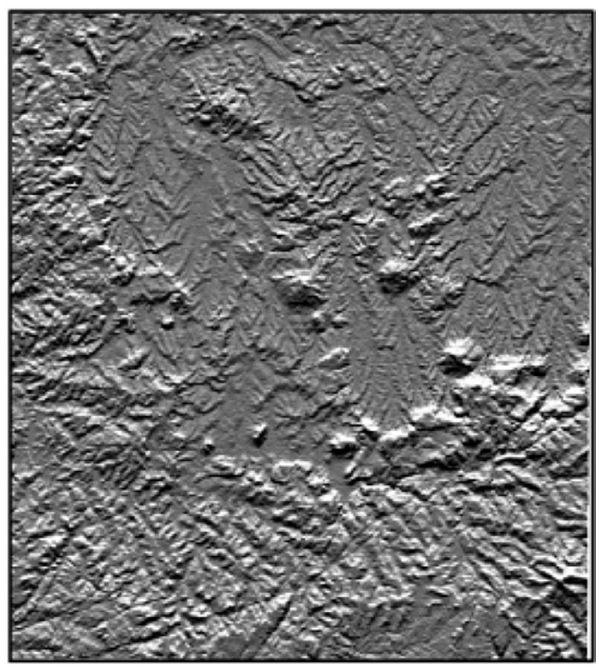

D

Figura 2. Mapas de relevo sombreado. Iluminantes situados a $35^{\circ}$, com azimutes Leste (A), Nordeste (B), Noroeste (C) e Norte (D).

de relevo sombreado, estes se mostraram mais adequados para a análise: primeiro, pela ausência de feições superficiais (vegetação, construções, estradas etc.) que interferem na interpretação; segundo, por permitirem diferentes posições de iluminação, o que favorece o contraste de lineamentos orientados em todas as direções.

Foram elaborados diagramas de rosácea de frequências e comprimentos acumulados, agrupados em classes de $10^{\circ}$, visando uma avaliação estatística dos lineamentos interpretados e a determinação das orientações preferenciais.
Para esse tipo de análise, utilizou-se de uma ferramenta externa existente no programa ArcGis.

\section{Resultados obtidos}

A análise dos mapas de relevo sombreado ressalta lineamentos em escala regional (4 - $50 \mathrm{~km})$, observáveis em escalas menores do que 1:300.000, que não se destacam na imagem de satélite. Foi gerado inicialmente um mapa contemplando somente esses lineamentos (Figura 3). Desta- 
cam-se, em comprimento, as direções N60-70E e N40-60W e, em frequência, N50-70E e N10-30E. Esta diferença se deve à presença de lineamentos regionais, de ocorrência isolada, de orientação dominante NW e, secundariamente, ENE, que atravessam a área, englobando praticamente todas as unidades geológicas.

A análise pormenorizada do modelo buscou explorar o máximo de detalhamento permitido, com escala em torno de 1:50.000. Destacam-se, uma vez mais, no mapa com to- dos os lineamentos extraídos dos modelos de relevo sombreado (Figura 4), em comprimento acumulado, as direções N20-30NE, N50-70E, N0-10W e N40-50W, porém na rosácea de frequência acumulada, destacam-se as direções N60-70E e N40-50W, enquanto as direções N0-10W e N20-30E aparecem subordinadas. A diferença entre os diagramas se deve à presença de lineamentos em escala regional com direção próxima de N-S, que ocorrem preferencialmente na região central da área.
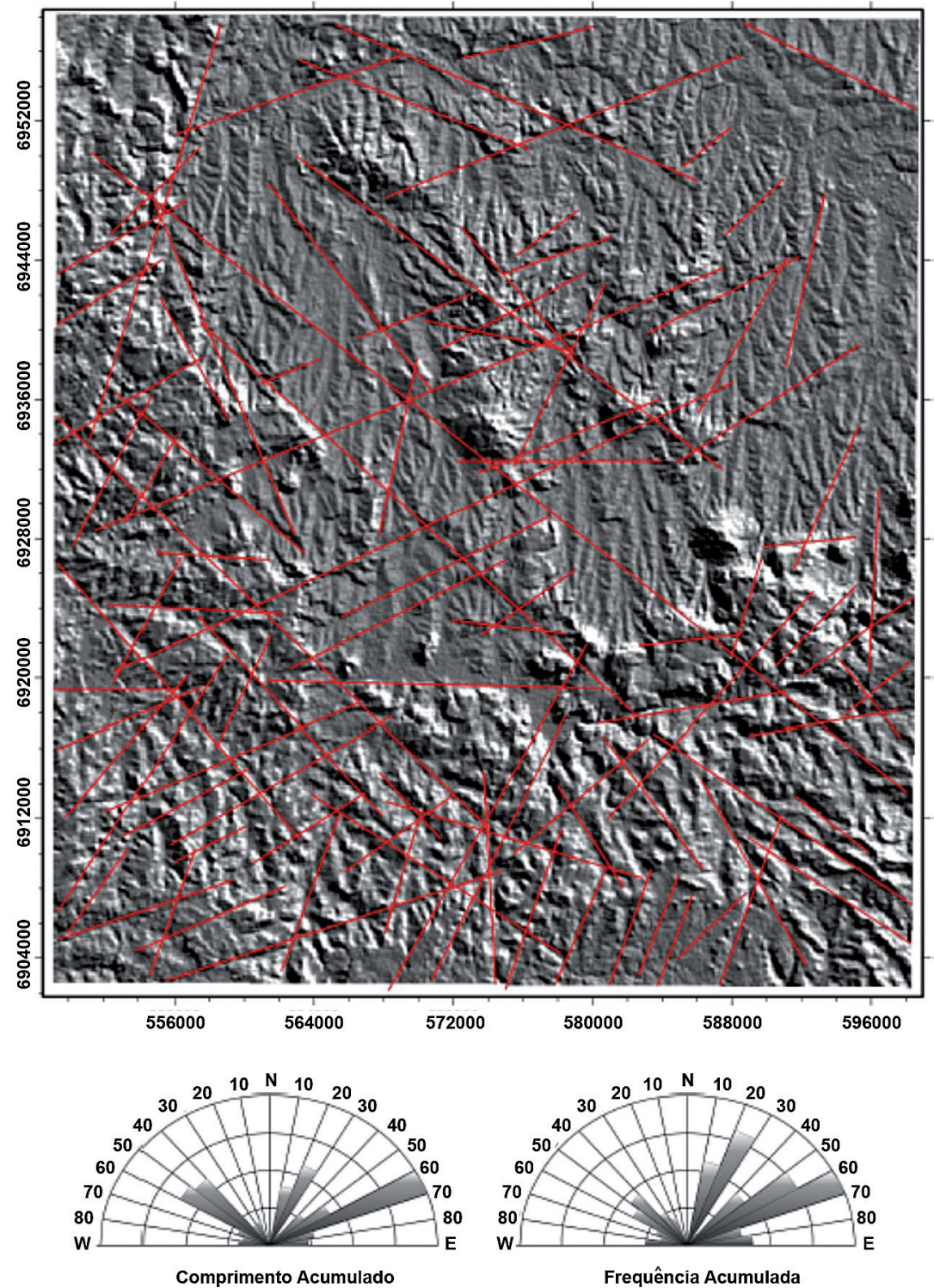

Figura 3. Mapa com os grandes lineamentos (4 - $40 \mathrm{~km}$ ) interpretados a partir de mapas de relevo sombreado. 

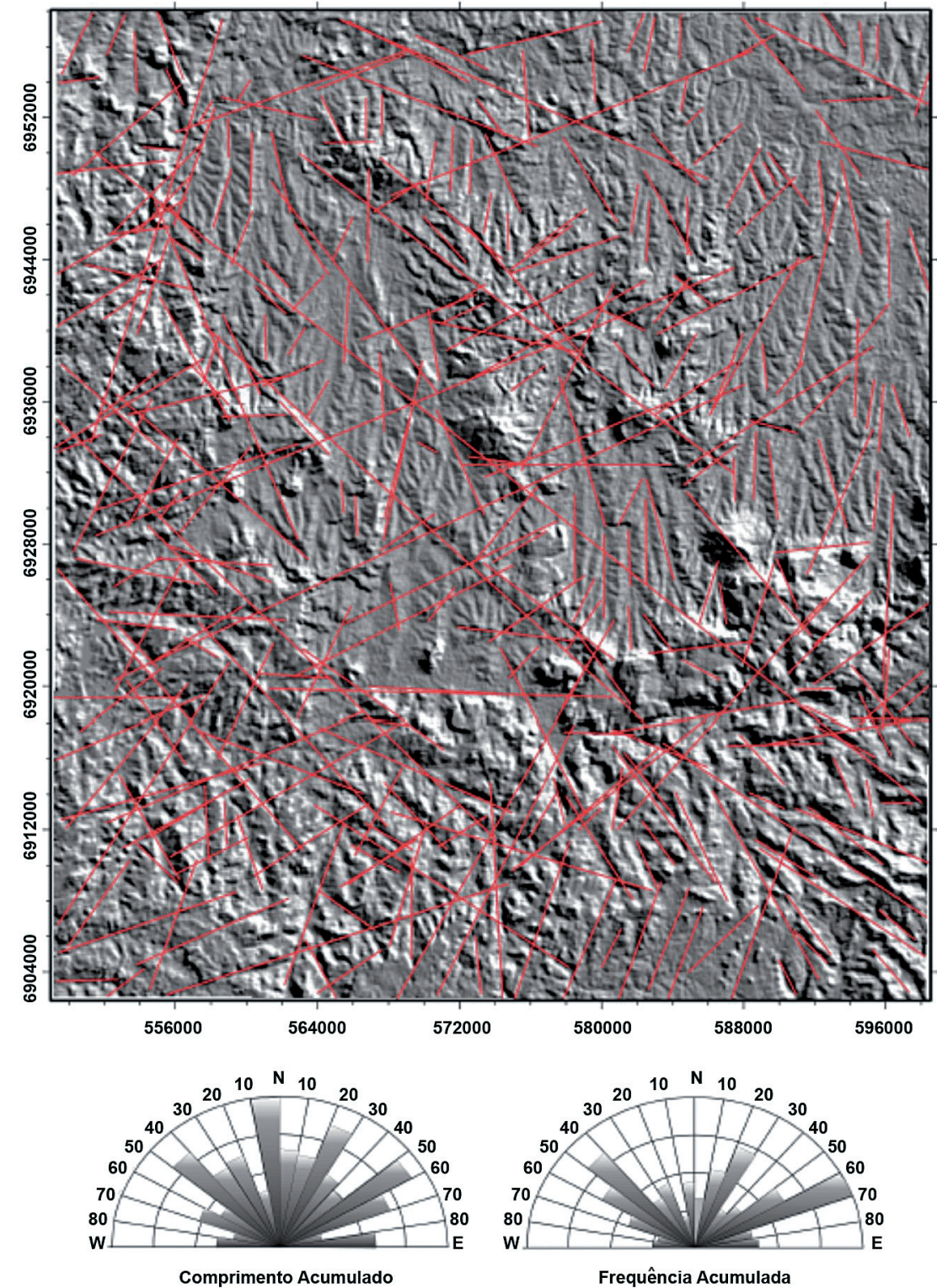

Figura 4. Mapa com todos os lineamentos extraídos dos mapas de relevo sombreado. 
A interpretação da imagem de satélite (Figura 5), apesar de não ressaltar os lineamentos mais longos, permite um maior detalhamento e mostra os lineamentos menores, porém com maior grau de dispersão nas direções. Destacam-se, em comprimento e frequência acumulados, as direções N0-10W e N20-30W, que contrastam com as orientações obtidas a partir dos mapas de relevo sombreados. Por fim, todos os dados obtidos foram integrados num mapa final (Figura 6), tomando-se o cuidado de eliminar os lineamentos repetidos para evitar um falseamento da análise. As direções que revelaram maior comprimento acumulado foram N40-60 W, N60-70E e N10-30E, e, frequência acumulada, N0-10W, N20-50W e N20-30E.

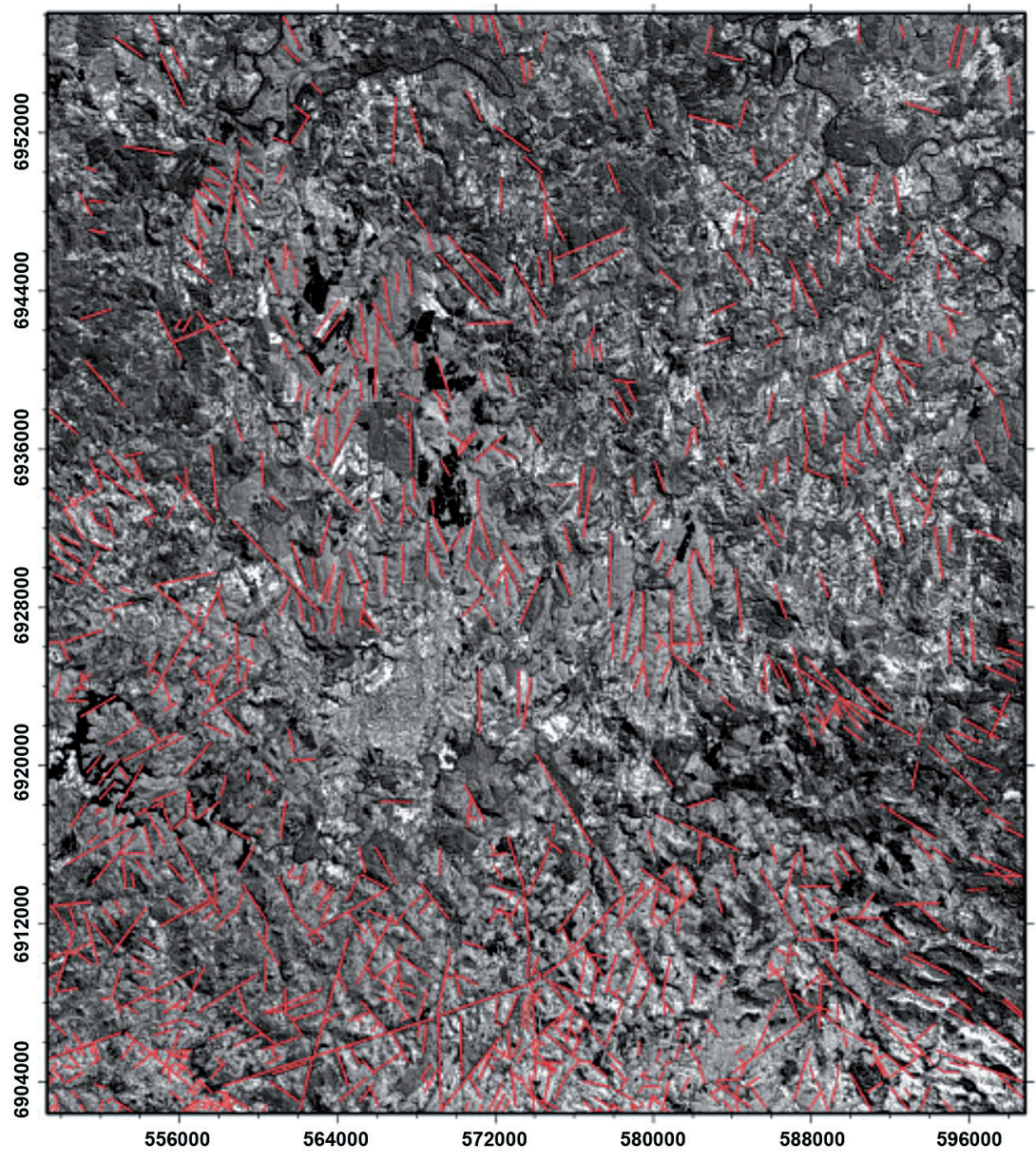

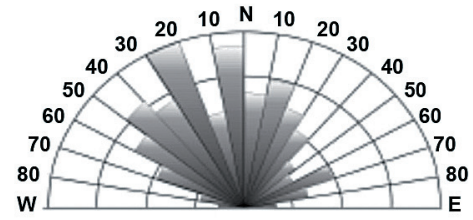

Comprimento Acumulado

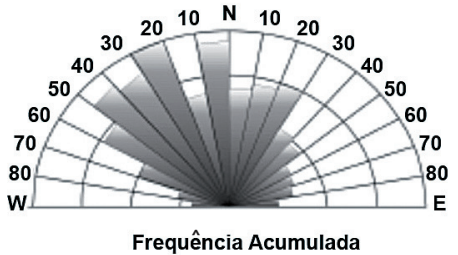

Frequência Acumulada

Figura 5. Mapa com os lineamentos extraídos de imagem de satélite Landsat-tm, pancromática. 


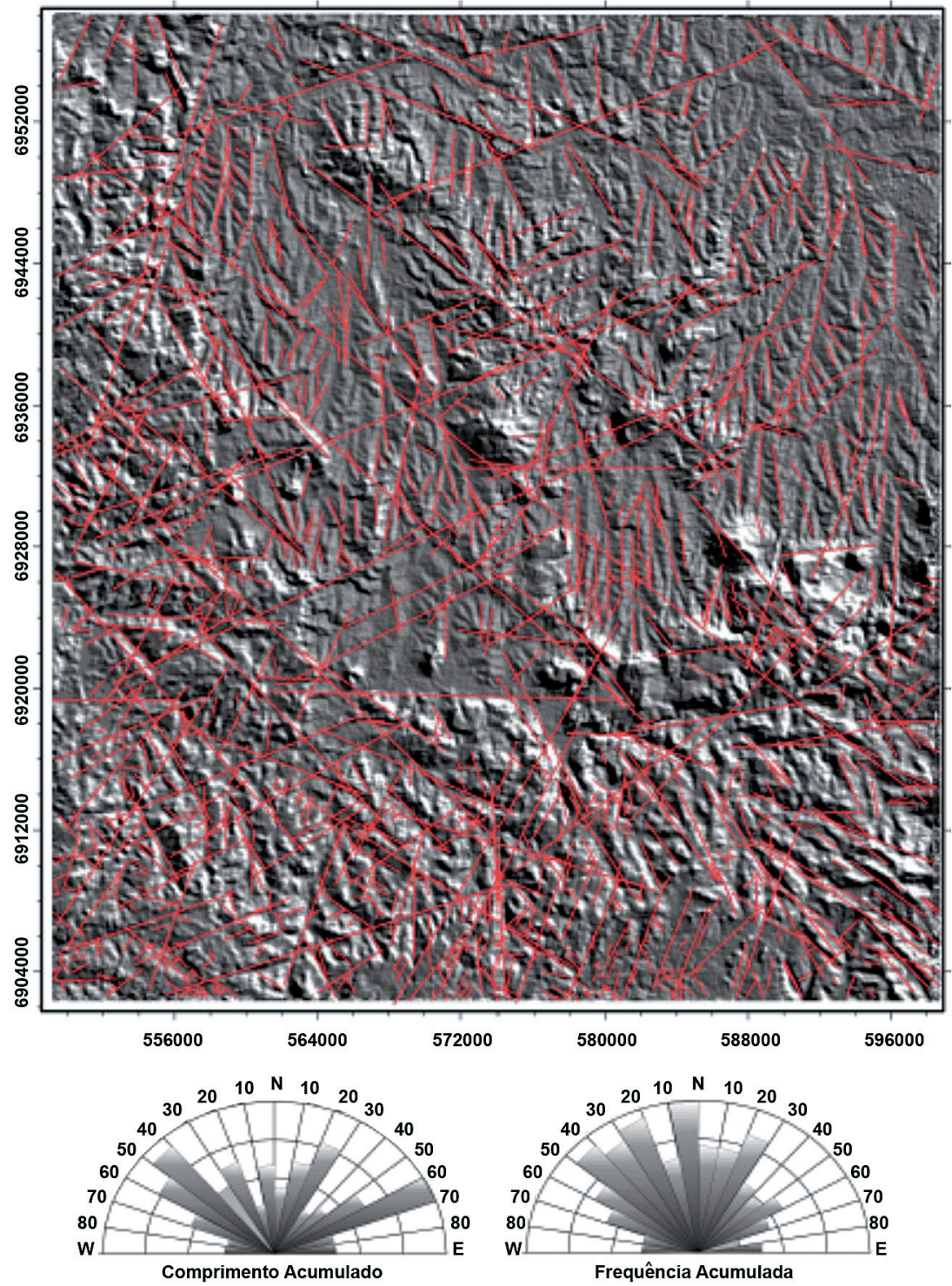

Figura 6. Mapa com a somatória dos lineamentos extraídos dos mapas de relevo sombreado e da imagem de satélite. 


\section{DISCUSSÃO}

De modo geral, a análise dos lineamentos demonstrou que os mapas de relevo sombreado forneceram melhores resultados do que a imagem de satélite, sobretudo no que se referem aos lineamentos mais expressivos, de ordem quilométrica (4 a $40 \mathrm{~km}$ ), associados provavelmente com estruturas de maior importância no contexto tectônico regional.

Os mapas de relevo sombreado destacaram preferencialmente as direções NNE, ENE e NW, enquanto a imagem ressaltou mais as direções N-S, NNW e WSW. A análise integrada das duas bases apontou maior frequência acumulada nas direções WNW, NNE e N-S, sendo as duas primeiras influenciadas pelo elevado número de lineamentos menores com esta direção extraído da imagem de satélite, enquanto os comprimentos maiores acumulados nas direções ENE, NNE e NW foram influenciados pelos lineamentos maiores, de ordem quilométrica, obtidos a partir dos mapas de relevo sombreado.

A análise revelou também alguns aspectos importantes na distribuição espacial dos lineamentos na área, dentre os quais, destacam-se: a) repetição sistemática dos grandes lineamentos NW, marcados em escala regional, e que afetam todas as unidades geológicas da região; b) presença de lineamentos de ordem quilométrica $\mathrm{NE}$, que afetam várias unidades, e que não são tão salientes como os de direção NW; c) existência nos domínios da Formação Geral de lineamentos de direção NNE, que são menos frequentes nas outras unidades, particularmente no extremo sul da área, onde possuem direção sistemática e destacam-se em ambas às bases analisadas; d) lineamentos de direção N0-10W, que se sobressaem na porção central da área, no domínio das rochas sedimentares da bacia, assim como os de direção NNW, relativamente menores, que são observados, sobretudo na imagem de satélite. Tais lineamentos controlam os afluentes (sistematicamente retilíneos) dos rios que drenam para norte e nordeste em direção ao rio Canoas.

A presença na região do Domo de Lages de lineamentos com direções NW, NNE, NE, ENE e E-W, afetando rochas vulcânicas da Formação Serra Geral, indica que houve reativação tectônica de uma matriz estrutural mais antiga, uma vez que a maioria destas direções é também encontrada na sequência gondwânica da Bacia do Paraná e no seu embasamento (Soares et al., 1982, 1996; Almeida, 1983; Zalán et al., 1987, 1990; Ferreira e Almeida, 1989; Rostirolla et al., 2000; Freitas, Rostirolla, Ferreira, 2005; Strugale et al., 2007, dentre outros). A idade máxima para esse evento tem sido considerada como do EoCretáceo (Zalán et al., 1987; Freitas, Rostirolla, Ferreira, 2005; Strugale et al., 2007, dentre outros). No entanto, como tais orientações estruturais afetam também as rochas alcalinas do Domo de Lages, cuja idade (K/Ar e $\mathrm{Rb} / \mathrm{Sr}$ ) si- tua-se entre 61 e $81 \mathrm{Ma}$ (Scheibe et al., 1985), conclui-se que a idade máxima para o referido evento situa-se no limite Cretáceo/Paleógeno, ou, eventualmente, podendo ser até mais nova, possivelmente do Neógeno.

Estudos estruturais, realizados na região de Lages, descrevem transcorrências destrais NNE, NE e N-S, e sinistrais WNW e E-W (Roldan, 2007). O autor relaciona estas transcorrências a um regime compressivo NE-SW, que teria atuado durante a estruturação do domo e também após a intrusão e resfriamento das rochas alcalinas, situando, portanto, a geração destas falhas na passagem do Cretáceo para o Paleógeno. Esta orientação do regime compressivo difere um pouco da orientação da fase deformacional D2 - com tensão principal orientada WSW-ENE - provavelmente de mesma idade, definida na região do Arco de Ponta Grossa por Strugale et al. (2003, 2007), que é também similar (em idade e campo de tensão) ao evento $D 2$, definido por Freitas e Rostirolla (2005), a partir de estudos realizados na divisa do Paraná com Santa Catarina.

Mapas geofísicos (magnetométricos e gravimétricos) e de sensores remotos, disponíveis a partir de áreas do embasamento e da bacia, na porção sul do Paraná e na parte norte de Santa Catarina, mostram lineamentos concordantes com os padrões estruturais reportados na literatura e delineados em mapas tectônicos regionais, e realçam os padrões NE (N60-70E e N30-40E), NW, NNW e E-W, com alguns deles de continuidade regional, a exemplo deste último que aparece restrito a 'corredores' (Freitas e Rostirolla, 2005). Os dois primeiros padrões figuram no mapa de lineamentos da porção oriental de Santa Catarina, apresentado por Scheibe (1979), com realce para os lineamentos de Corupá, Rio do Sul e Engano (NE e ENE), Rio Hercílio, Serra Geral e Rio Canoas (NW) (ver Figura 1B).

Os padrões de lineamentos NE e NNE aparecem como os mais importantes e representam descontinuidades mais antigas do embasamento, que foram recorrentemente ativas e controlaram a evolução sedimentar e tectônica da bacia. $\mathrm{O}$ padrão estrutural NE aparece também como um dos padrões estruturais com o mais elevado índice de concordância no mapa de lineamentos estruturais interpretado a partir de fontes diferentes, como modelo digital de terreno, imagens de satélite, mapas magnéticos e gravimétricos (Soares et al., 2007). Por outro lado, os lineamentos E-W foram ativos provavelmente a partir do Triássico (Zalán et al., 1987, 1990), sendo depois reativados no Cretáceo como falhas transcorrentes sinistrais, a exemplo da região de Jaguariaíva, onde estas estruturas são consideradas mais novas do que as transcorrências sinistrais (NE e NW) e destrais (NE), reconhecidas também nas regiões de Quatiguá e Prudentópolis (Rostirolla et al., 2000; Freitas e Rostirolla, 2005; Machado e Rostirolla, 2005; Mezzomo e Rostirolla, 2005; Santos, 2005). 


\section{CONCLUSÕES}

Os resultados aqui obtidos evidenciaram as vantagens do uso de mapas de relevo sombreado em relação às imagens de satélite LANDSAT-TM (banda 8, pancromática) no estudo estrutural de regiões de bacias sedimentares, em particular na investigação de estruturas regionais, uma vez que as imagens não permitem destacar estruturas observáveis em escalas menores do que 1:300.000. Os mapas de relevo sombreado realçam os lineamentos regionais (4 - $50 \mathrm{~km})$ associados à região do Domo de Lages, em particular os de direção N60-70E, N20-30E, N0-10W e N40-50W (Figuras 3 e 4), enquanto as imagens de satélite LANDSAT-TM ressaltaram os lineamentos menores $(1-3 \mathrm{~km})$ com direções principalmente N20-30W, N0-10W e N10-20E (Figura 5).

Muitas das direções estruturais extraídas das duas bases digitais, particularmente as de direção NW, NNE, NE, ENE e E-W, apresentam movimentação transcorrente, destral e sinistral. São estruturas geradas em grande parte por reativação de estruturas anteriores presentes tanto na sucessão sedimentar gondwânica da bacia, como no seu embasamento pré-cambriano, a exemplo do que ocorre em outros altos estruturais descritos na Bacia do Paraná, como o de Quatiguá, no Paraná, e o de Pitanga, em São Paulo. A idade dessas orientações estruturais no Domo de Lages é no máximo Eo-Cretáceo/Paleógeno ou até mesmo do Neógeno, uma vez que elas afetam a estrutura do domo e as rochas alcalinas a ele associadas.

A direção de tensão principal (NE-SW) proposta para a geração do domo e das transcorrências associadas é ligeiramente diferente daquela considerada para a fase deformacional (ou evento) D2, aparentemente de mesma idade, definida no Arco de Ponta Grossa e na região limítrofe do estado do Paraná com Santa Catarina. Essa variação no campo de tensão regional pode ser explicada por heterogeneidades do padrão estrutural do embasamento (falhas e zonas de cisalhamento anastomosadas, descontinuidade das estruturas, interferência de outros padrões estruturais etc.), aspecto este que exerce forte influência na partição da deformação regional.

A estruturação do Domo de Lages parece associar-se com a reativação de estruturas secundárias NW, presentes no embasamento do escudo catarinense, algumas delas com evidências de atividade mais antiga, provavelmente no Eo-Cretáceo. Tais estruturas condicionaram a colocação de diques básicos relacionados à Formação Serra Geral, a exemplo do que ocorre nas estruturas NW na região do Arco de Ponta Grossa, também de idade eo-cretácica, que serviram de condutos para a extrusão do magmatismo básico da Formação Serra Geral.

A situação tectônica do Domo de Lages entre duas estruturas regionais importantes - o Arco de Ponta Grossa e o Sinclinal de Torres - já salientado por outros autores, em conjunto com as novas informações geológicas e estruturais apresentadas neste trabalho, sugere uma ligação ao mesmo evento tectônico regional, relacionado ao rifteamento continental do Gondwana e evolução da margem continental brasileira. No entanto, a estruturação do domo parece estar vinculada a um estágio mais avançado desse processo, de forma análoga ao que tem sido proposto recentemente.

\section{AGRADECIMENTOS}

Os autores externam seus agradecimentos à Prefeitura Municipal de Lages, SC, em particular ao ex-Prefeito de Lages Raimundo Colombo, e ao $10^{\circ}$ Batalhão de Engenharia de Construção de Lages, particularmente aos então Cels. Nestor Carmelho Ravieri e Alexandre Rui Baralho Bianco, pelo apoio de infraestrutura fornecido durante o desenvolvimento das atividades de campo do projeto, ao CNPq, pela concessão de uma Bolsa de Produtividade em Pesquisa a um dos autores do trabalho (Proc. 300423/82-9, de R. Machado), e a Thelma Samara, da Seção de Ilustração do Instituto de Geociências da USP, pela confecção de várias figuras que ilustram o artigo.

\section{REFERÊNCIAS}

ALMEIDA, F. F. M. Diferenciação tectônica da Plataforma Brasileira. In: CONGRESSO BRASILEIRO DE GEOLOGIA, 23., 1969, Salvador. Anais... Salvador: SBG, 1969, p. 29-46.

ALMEIDA F. F. M. Relações tectônicas das rochas alcalinas mesozóicas da região meridional da Plataforma SulAmericana. Revista Brasileira de Geociências, São Paulo, v. 13, n. 3, p.139-158, 1983.

BATISTA, M. J.; MORALES, N.; SOUSA, M. O. L. Caracterização Estrutural do Sistema Horst-Graben de JiboiaRegião Central do Estado de São Paulo. In: CONGRESSO BRASILEIRO DE GEOLOGIA, 41., 2002, João Pessoa. Anais... João Pessoa: SBG, 2002, p. 618-618.

CAMPOS, A. F.; RIGOTI, A.; ROSTIROLLA, S.P.; BARTOSZECK, M.K. Assinatura geoelétrica de fraturas: estudo de caso no Grupo Itararé - Bacia do Paraná. In: SIMPÓSIO NACIONAL DE ESTUDOS TECTÔNICOS, 10/ INTERNATIONAL SYMPOSIUM ON TECTONICS, 4 ., 2005, Curitiba. Boletim de Resumos Expandidos... Curitiba: SBG, 2005, v.1, p.21-24.

COMIN-CHIARAMONTI, P.; GOMES, C. de B.; CASTORINA, F.; CENSI, P. di; ANTONINI, P.; 
FURTADO, S.; RUBERTI, E.; SCHEIBE, L. F. Geochemistry and geodynamic implications of the Anitápolis and Lages alkaline-carbonatite complexes, Santa Catarina State, Brazil. Revista Brasileira de Geociências, São Paulo, v. 32, n.1, p. 43-58, 2002.

COMIN-CHIARAMONTI, P.; GOMES, B. G.; MARQUES, L. S.; CENSI, P.; RUBERTI, E.; ANTONINI, P. Carbonatites from southeastern Brazil: Sr-Nd-Pb systematics. In: SOUTH-AMERICAN SYMPOSIUM ON ISOTOPE GEOLOGY, 4., 2003, Salvador. Short Papers... Salvador, v. 2, 2003, p. 520-523.

FERREIRA, A. C.; ALMEIDA, T. I. R. Tectônica transcorrente e imagens TM-Landsat aplicadas à prospecção de fluorita e barita em Santa Catarina. Revista Brasileira de Geociências, São Paulo, v. 19, n. 2, p. 207-223, 1989.

FERREIRA, F. J. F.; MONMA, R.; CAMPANHA, C. A. G.; GALLI, V. L. An Estimate of the Degree of Crustal Extension and Thinning Associated with the Guapiara Lineament Based on Aeromagnetic and Gravimetric Modelling. Boletim do IG-USP. Série Científica, São Paulo, v. 20, n. 1, p. 69-70, 1989.

FREITAS, R. C.; ROSTIROLLA, S. P. Análise comparativa entre estruturas do embasamento e resposta em superfície na Bacia do Paraná, região entre os Estados do Paraná e Santa Catarina. In: SIMPÓSIO NACIONAL DE ESTUDOS TECTÔNICOS, 10; INTERNATIONAL SYMPOSIUM ON TECTONICS, 4., 2005, Curitiba. Boletim de Resumos Expandidos... Curitiba: SBG, 2005, v. 1, p. 41-44.

FREITAS, R. C.; ROSTIROLLA, S. P.; FERREIRA, F. J. F. Geoprocessamento multitemático e análise estrutural no sistema petrolífero Irati -Rio Bonito, Bacia do Paraná. Boletim de Geociências da Petrobrás, v. 14, p. 71-93, 2005.

GROHMANN, C. H.; STEINER, S. S. SRTM resample with Short Distance-Low Nugget Kriging. In: INTERNATIONAL SYMPOSIUM ON TERRAIN ANALYSIS AND DIGITAL TERRAIN MODELLING, 2006, Nanjing, China. Proceedings... China, 2006. 1 CD-ROM.

HACHIRO, J.; COUTINHO, J. M. V.; FRASCÁ, M. H. B. O.; MENEZES, C. M. O astroblema de Vargeão (SC): evidências petrográficas de um crateramento criptoexplosivo por petardo extraterrestre. In: SIMPÓSIO BRASILEIRO DE GEOlOGIA, 3., 1993, Rio de Janeiro. Atas... Rio de Janeiro: SBG,1993, p. 276-283.
HACHIRO, J.; COUTINHO, J. M. V.; RICCOMINI, C.; COIMBRA, A. M.; FERNANDES, L. A. O Astroblema de Piratininga (São Paulo, Brasil). In: SIMPÓSIO SOBRE O CRETÁCEO DO BRASIL, 3., 1994, Rio Claro. Boletim de Resumos... Rio Claro: SBG, 1994, p. 93-96.

LIU, C. C. Análise estrutural de lineamentos em imagens de sensoriamento remoto: aplicação ao estado do Rio de Janeiro. 1984. 157 f. Tese (Doutorado) - Instituto de Geociências, Universidade de São Paulo, São Paulo, 1984.

LIU, C. C. A geologia estrutural do estado do Rio de Janeiro, vista através de imagens MSS do Landsat. In: SIMPÓSIO DE GEOLOGIA , 1., 1987, Rio de Janeiro. Anais... Rio de Janeiro: SBG, Núcleo RJ-ES, 1987, p. 164-168.

LOCZY, L. Evolução paleogeográfica e geotectônica da Bacia Gondwânica do Paraná e seu embasamento. Boletim do Departamento Nacional da Produção Mineral- Divisão de Geologia e Mineralogia, Rio de Janeiro, p. 1-234, 1966.

LOCZY, L. Basic and alkalic volcanics of the State of Santa Catarina. Anais da Academia Brasileira de Ciências, Rio de Janeiro, v. 40, p.187-193, 1968. Suplemento.

MACHADO, F. G.; ROSTIROLLA, S. P. Caracterização estrutural preliminar da área de Jaguariaíva, Bacia do Paraná. In: SIMPÓSIO NACIONAL DE ESTUDOS TECTÔNICOS, 10 / INTERNATIONAL SYMPOSIUM ON TECTONICS, 4., 2005, Curitiba. Boletim de Resumos Expandidos... Curitiba: SBG, 2005, p. 38-40.

MEZZOMO, E.; ROSTIROLLA, S. P. Delimitação do arcabouço estrutural na porção centro leste do Paraná, Bacia do Paraná, com base na análise de sensores remotos, estudos de campo e modelagem estrutural tridimensional. In: SIMPÓSIO NACIONAL DE ESTUDOS TECTÔNICOS, 10 / INTERNATIONAL SYMPOSIUM ON TECTONICS, 4., 2005. Curitiba. Boletim de Resumos Expandidos... Curitiba: SBG, 2005, p. 35-39.

O'LEARY, D. W.; FRIEDMAN, J. D.; POHN, H. A. Lineament, linear, lineation: some proposed new standards for old terms. Geological Society American Bulletin, New York, v. 87, p.1463-1469, 1976.

PORTELA FILHO, C. V. ; FERREIRA, F. J. F.; ROSA FILHO, E. F.; ROSTIROLLA, S. P. Compartimentação magnética-estrutural do sistema aqüífero serra geral e sua conectividade com o sistema aqüífero guarani na região central do arco de ponta grossa (Bacia do Para- 
ná). Revista Brasileira de Geociências, São Paulo, v. 35, p.369-381, 2005.

PUTZER, H. Camada de carvão e seu comportamento nos sul de Santa Catarina. Boletim do Departamento Nacional da Produção Mineral. Divisão de Fomento e Produção Mineral, Rio de Janeiro, n. 91, 1-182, 1952.

RICCOMINI, C.; CRÓSTA, A. P. Análise preliminar de lineamentos em produtos de sensores remotos aplicada à prospecção mineral na área dos granitóides Mandira, SP. Boletim IG-USP. Série Científica, São Paulo, v. 19, p. 23-37, 1988.

RICCOMINI, C.; POHL, L. L.; FELISBINO JR, S. E.; FAMBRINI, G. L.; SANT'ANNA, L. G. Tectônica transcorrente na Bacia do Paraná: o exemplo da Zona de Cisalhamento de Paraisolândia, SP. In: SIMPÓSIO DE GEOLOGIA DO SUDESTE, 2., 1991, São Paulo. Atas... São Paulo: SBG, 1991, p. 181-182.

RICCOMINI, C.; MANCINI, F.; HASEBE, F. K.; RIDENTE JR.; SANT'ANNA, L. G.; FAMBRINI, G. L. Evidência de neotectonismo no Vale do Rio Passa Cinco, Domo de Pitanga, Bacia do Paraná. In: SIMPÓSIO DE GEOLOGIA DO SUDESTE, 2., 1991, São Paulo. Atas... São Paulo: SBG, 1991, p. 27-28.

RICCOMINI, C. Estilos estruturais da região do Domo de Pitanga, Bacia do Paraná, SP. Boletim do Instituto de Geociências da USP, São Paulo, v. 12, p. 93-94, 1992.

RICCOMINI, C. Tectonismo gerador e deformador dos depósitos sedimentares Pós-Gondvânicos da porção centro-oriental do estado de São Paulo e áreas vizinhas. 1995. 100 f. Tese (Livre Docência) - Instituto de Geociências, Universidade de São Paulo, São Paulo, 1995.

RICCOMINI, C.; VELÁZQUEZ, V. F.; GOMES, C. B. Tectonic controls of the Mesozoic and Cenozoic alkaline magmatism in central-southeastern Brazilian Platform. In: GOMES, C. B.; COMIN-CHIARAMONTI, P. Mesozoic to Cenozoic alkaline magmatism in the Brazilian Platform. São Paulo: EDUSP-FAPESP, 2005, p. 31-55.

ROLDAN, L. F. Tectônica Rúptil Meso-Cenozóica na região do Domo de Lages, SC. 2007. 121 f. Dissertação (Mestrado) - Instituto de Geociências, Universidade de São Paulo, São Paulo, 2007.

ROSTIROLLA, S. P.; ASSINE, M. L.; FERNANDES, L. A.; ARTUR, P. C. Reativação de Paleolineamentos duran- te a evolução da Bacia do Paraná - o exemplo do Domo de Quatiguá. Revista Brasileira de Geociências, São Paulo, v. 30, n. 4, p.1-15, 2000.

SANTOS, C. T. Arcabouço estrutural da folha Prudentópolis - PR (1:50.000). In: SIMPÓSIO NACIONAL DE ESTUDOS TECTÔNICOS, 10 / INTERNATIONAL SYMPOSIUM ON TECTONICS, 4., 2005, Curitiba. Boletim de Resumos Expandidos... Curitiba: SBG, 2005, p. 32-34.

SCHEIBE, L. F. Estudo Petrológico e Geoquímico dos Carbonatitos da Fazenda Varela, Lages, SC, Brasil. 1979. 120 f. Dissertação (Mestrado) - Instituto de Geociências, Universidade Federal do Rio Grande do Sul, Rio Grande do Sul, 1979.

SCHEIBE, L. F. Geologia e Petrologia do Distrito Alcalino de Lages, SC. 1986. 224 f. Tese (Doutorado) - Instituto de Geociências, Universidade de São Paulo, São Paulo, 1986 .

SCHEIBE, L. F. ; KAWASHITA, K. ; GOMES, C. B. Contribuição à geocronologia do Complexo Alcalino de Lages, SC. In: SIMPÓSIO SUL-BRASILEIRO DE GEOLOGIA, 2., 1985, Florianópolis. Anais... Florianópolis: SBG, 1985, p. 299-307.

SCHOBBENHAUS, C.; CAMPOS, D. A.; DERZE, G. R.; ASMUS, H. E. Geologia do Brasil: texto explicativo do Mapa Geológico do Brasil e da Área Oceânica adjacente incluindo depósitos minerais. Brasília: DNPM-MME, 1984, 501 p. Escala 1: 2.500.000.

SOARES, A.P.; SOARES, P. C.; BETTÚ, D. F.; HOLZ, M. Compartimentação estrutural da Bacia do Paraná: a questão dos lineamentos e sua influência na distribuição do Sistema Aquífero Guarani. Geociências UNESP, São Paulo, v. 26, n. 4, p. 297-311, 2007.

SOARES, P. C. Elementos estruturais da parte nordeste da Bacia do Paraná: classificação de gênese. In: CONGRESSO BRASILEIRO DE GEOLOGIA, 28., 1974, Porto Alegre. Anais... Porto Alegre: SBG, 1974, v. 1, p. 107-121.

SOARES, P. C. Elementos estruturais da parte nordeste da Bacia do Paraná: classificação de gênese. In: CONGRESSO BRASILEIRO DE GEOLOGIA, 28., 1976, Porto Alegre. Anais... Porto Alegre: SBG, 1976, v. 1, p. 107-121.

SOARES, P. C.; BARCELLOS, P. E.; CSORDAS, S. M. Análise, interpretação e integração de lineamentos a partir de imagens (Radar-Landsat) e suas relações com a tectô- 
nica da Bacia do Paraná. São Paulo: Paulipetro/ Consórcio CESP/IPT, 1982. Relatório RT-342/82.

SOARES, P. C.; ROSTIROLLA, S. P.; FERREIRA, F. J. F.; STEVANATO, R. The Pitanga-Quatingua-Jacutinga structural high in the Paraná Basin: a lithospheric structure. In: THEMATIC SYMPOSIUM ON TECTONICS AND SEDIMENTATION IN SOUTH AMERICAN BASINS, First Annual Conference of IGCP Project 381, 1996, Salvador. Extended Abstracts... Salvador: IGCP,1996, p. 80-82.

SOUSA, M. O. L. Caracterização Estrutural do Domo de Pitanga. 1997. 116 f. Dissertação (Mestrado) - Instituto de Geociências e Ciências Exatas de Rio Claro, UNESP, Rio Claro, 1998.

SOUSA, M. O. L. Caracterização Estrutural dos altos estruturais de Pitanga, Artemis, Pau D'Alho e Jibóia, centro do Estado de São Paulo. 2002. 206 f. Tese (Doutorado) Instituto de Geociências e Ciências Exatas de Rio Claro, UNESP, Rio Claro, 2002.

SOUSA, M. O. L.; MORALES, N. Evolução tectônica do Alto Estrutural de Pitanga - SP. In: SIMPÓSIO NACIONAL DE ESTUDOS TECTÔNICOS; SIMPÓSIO INTERNACIONAL DE TECTÔNICA, 7., 1999. LençóisBA. Anais...Lençóis: SBG, 1999, p. 40-42.

SOUSA, M. O. L.; MORALES, N. Feições neotectônicas presentes na região dos altos estruturais de Pitanga, Artemis, Pau D'Alho e Jibóia, centro do estado de São Paulo. In: SIMPÓSIO DE GEOLOGIA DO SUDESTE, 8., São Pedro - SP, 2003. Boletim de Resumos... São Pedro: SBG, 2003, p. 90-90.

SOUSA, M. O. L.; MORALES, N.; BAPTISTA, M. J. Reconhecimento de inclinações de camadas com alto ângulo associadas às falhas normais da Estrutura de Jibóia-Centro do estado de São Paulo. In: SIMPÓSIO DE GEOLOGIA DO SUDESTE, 8., 2003, São Pedro-SP. Boletim de Resumos... São Pedro: SBG, 2003, p. 62.

STRUGALE, M.; ROSTIROLLA, S. P.; KULEVICZ, M. B.; MANCINI, F. Evolução estrutural do Arco de Ponta Grossa no Cretáceo a partir da análise de estruturas rúpteis no Grupo São Bento (Bacia do Paraná). In: SIMPÓSIO NACIONAL DE ESTUDOS TECTÔNICOS, 9., 2003, Armação de Búzios - RJ. Boletim de Resumos... Armação de Búzios: SBG, 2003, p. 320-323.

STRUGALE, M.; ROSTIROLLA, S. P.; MANCINI, F.; PORTELA FILHO, C. V.; FERREIRA, F. J. F.; FREITAS,
R. C. Structural framework and Mesozoic-Cenozoic evolution of Ponta Grossa Arch, Paraná Basin, southern Brazil. Journal of South American Earth Sciences, Oxford, v. 24, p. 203-227, 2007.

STEINER, S. Cartografia e modelamento digital da região de Lages, SC. 2004. 47 f. Trabalho de Formatura - Instituto de Geociências da Universidade de São Paulo, São Paulo, 2004.

ZALÁN, P. V.; WOLFF, S.; CONCEIÇÃO, J. C. J.; VIEIRA, I. S.; APPI, V. T.; ZANOTTO, O. A. Tectônica e Sedimentação da Bacia do Paraná. In: SIMPÓSIO SULBRASILEIRO DE GEOLOGIA, 3., 1987, Curitiba. Atas... Curitiba: SBG, 1987, p. 441-474.

ZALÁN, P. V.; WOLFF, S.; ASTOLFI, M. A. M.; VIEIRA, L. S.; CONCEIÇÂO, J. C. J.; APPI, V. T.; NETO, E. V. S.; CERQUEIRA, J. R.; MARQUESA, A. The Paraná Basin, Brazil. In: LEIGHTON, M. W.; KOLATA, D. R.; EIDEL, J. J. Interior cratonic basins. Tulsa: AAPG, 1990, p. 681-708. Memoir 51. 